\title{
How to Use the Paradox of Hedonism
}

\author{
Alexander Dietz | ORCID: oooo-0oo3-2469-2227 \\ School of English, Communication and Philosophy, \\ Cardiff University, Cardiff, Wales \\ DietzA4@cardiff.ac.uk
}

\begin{abstract}
The paradox of hedonism is the idea that intrinsically desiring nothing other than pleasure can prevent one from obtaining pleasure. In this article, I show how the paradox of hedonism can be used as the basis for an objection against hedonism about well-being, and one that is more defensible than has been commonly recognized. Moreover, I argue that the challenge presented by the paradox can be used to target not only hedonism about well-being, but also desire satisfactionism and the hybrid theory. However, I argue that certain sophisticated versions of all three theories can escape it.
\end{abstract}

\section{Keywords}

well-being - hedonism - paradox of hedonism

\section{$1 \quad$ Introduction}

One of the most prominent theories of well-being is hedonism. ${ }^{1}$ As a first pass, we can understand this view as follows:

Hedonism: What is intrinsically good for someone is (just) the pleasure they experience; what is intrinsically bad for someone is (just) the displeasure they experience.

1 For an introduction to hedonistic theories of well-being, see Gregory (2016). 
For present purposes, I will be using the language of intrinsic value to refer to the idea of what is valuable for its own sake, rather than because it will lead to other valuable things. Similarly, I will be using the term intrinsic desire to refer to the idea that one desires the object for its own sake, rather than because it will lead to something else which one desires. ${ }^{2}$

Hedonism has been subject to a number of objections. According to the philosophy of swine objection, hedonism has the implausible implication that taking pleasure in "base" pursuits, such as bestiality or in the mindless game of pushpin, may be just as good for us as more cultivated pursuits. According to the experience machine objection, hedonism has the implausible implication that a life spent in a machine creating the experience of a rich and fulfilling life might be just as good for one as the real thing.

In this paper, I am interested in another traditional issue for hedonism, the so-called paradox of hedonism. As a first pass, we can understand this idea as follows:

The paradox of hedonism: If one intrinsically desires nothing other than one's own pleasure, then one will be prevented from obtaining pleasure.

The paradox of hedonism is a familiar idea in moral philosophy; the classic statement of the paradox, by Joseph Butler, dates back to $1726 .{ }^{3}$ But the paradox of hedonism has not been recognized in the recent literature as representing an important objection to hedonism about well-being. In fact, in recent general discussions of hedonism about well-being, the paradox of hedonism is often not even mentioned. ${ }^{4}$

I think that there is something intuitively compelling about the idea that the paradox of hedonism could pose a problem for hedonism about well-being, and I want to see how far it can be taken. My aim in this paper, then, is to develop a

2 Note that other terms are sometimes used for these concepts: "intrinsic" value in my sense is sometimes called "basic" value, and "intrinsic" desire in my sense is sometimes called "final" desire. This is because some argue that it is important to distinguish these concepts from the concept of something being valuable or desired just in virtue of its intrinsic properties. This distinction will come up again in sections 5 and 6. For introductions to the issues surrounding the concept of intrinsic value, see Rønnow-Rasmussen (2015) and Zimmerman and Bradley (2019).

3 See Butler (1726: 364-373). For a recent discussion, see Dietz (2019). Note that the phenomenon is meant to be "paradoxical" not in the strong sense of presenting us with an apparently sound argument leading to an absurd conclusion, but rather in the milder sense of being a surprising observation.

4 For example, the idea is not mentioned in Feldman (2004), a prominent book-length defense of hedonism about well-being; nor is it mentioned in Gregory (2016). 
clearer and more plausible version of the paradox of hedonism objection, and to make the case in its defense. We will then be in a better position to judge how forceful, and how interesting, the objection really is. ${ }^{5}$

I argue that the objection is indeed both more defensible and more interesting than has been commonly recognized. Roughly, the idea is this. The paradox is not merely an empirical problem of human psychology: even rational agents who accept hedonistic ethical views will end up running into the paradox. This is a problem for these views, we can argue, because it is reasonable to expect ethical theories to provide agents with advice that helps them to lead better lives, at least if the agents are rational. As we will see, this version of the objection does still rely on some controversial assumptions, but I argue that these assumptions are defensible.

In addition, I argue that the challenge presented by the paradox of hedonism, if it is indeed a problem at all, is also a more general problem than has been commonly recognized. As we will see, variants of the objection can be used to target not only hedonism, but also two of the other main camps in the debate over the nature of well-being: desire satisfaction theories and hybrid theories. However, I argue that certain sophisticated versions of all three types of theory can escape it.

\section{How to Formulate the Objection}

Butler describes the paradox of hedonism in stark terms. If self-love, or the desire for one's own happiness, "wholly engrosses us, and leaves no room for any other principle," he writes, "there can be absolutely no such thing at all as happiness, or enjoyment of any kind whatever." ${ }^{\prime 6}$ C. D. Broad finds Butler's observations "profoundly true and important": the "most wretched lives are led by men who have nothing to do but think of their own happiness and scheme for it." ${ }^{7}$ In his autobiography, John Stuart Mill reports having experienced the paradox firsthand in the form of a depression. "Ask yourself whether you are happy," he writes, "and you cease to be so."

But does this phenomenon, however unsettling, pose a problem for hedonism about welfare? There are several reasons why we might initially be skeptical.

5 This project, and the title of this paper, is inspired by Lin (2016a), an articulation and defense of the experience machine objection.

6 Butler (1726: 367$)$.

7 Broad (1930: 74).

8 Mill (1873: Chap. 5). 
First, it may just not be obvious how, exactly, the paradox of hedonism is supposed to provide us with an objection to hedonism about welfare. After all, the paradox of hedonism is a psychological claim, whereas hedonism about welfare is an ethical claim, so it is not clear how these claims could be in tension. What's the problem?

Second, more specifically, we might think that the paradox of hedonism is merely an empirical issue, and that merely empirical issues are generally not relevant to assessing philosophical theories. In other words, even if we could develop the objection into an argument against hedonism about welfare, such an argument would have to assume that it is reasonable to reject philosophical theories on empirical grounds, and we might be skeptical of this assumption. ${ }^{9}$

Third, we might think that the paradox of hedonism, if it is a problem at all, could only be a problem for egoistic hedonists. After all, as we have seen, the phenomenon is supposed to arise for those who desire only their own pleasure or happiness. As long as we are not egoists, then, perhaps we have nothing to worry about.

I will now argue, however, that we can understand the objection in a way that overcomes these worries. In order to do this, we first need to examine the paradox of hedonism phenomenon itself more closely. I will then lay out my version of the objection.

\subsection{Understanding the Paradox of Hedonism}

Before we consider the possible ethical implications of the paradox of hedonism, we first need to understand the nature of the paradox of hedonism phenomenon itself.

Why would intrinsically desiring nothing other than pleasure prevent one from obtaining pleasure? It is commonly assumed that this phenomenon, assuming that it is real, would have to be explained by contingent empirical facts, such as the difficulty of predicting what will make us happy. However, it is also possible that the paradox of hedonism has a deeper explanation..$^{10}$ In his classic discussion of the paradox, Butler suggests that the paradox of hedonism is a consequence of the nature of pleasure.

In particular, Butler suggests that the nature of pleasure involves a close connection to desire satisfaction, and that this is the key to understanding the paradox. In other words, Butler's account relies on an early version of a desire-based theory of pleasure, which remains a leading view in the

9 See Eggleston (2013a) and Cohen (2003).

$10 \operatorname{Dietz}(2019)$. 
contemporary literature, though it does face significant rivals. ${ }^{11}$ Butler's rough idea is that pleasure has to do with satisfying our desires, and so in order to obtain pleasure, we had better have independent desires to satisfy.

Now, developing this idea in a precise and defensible way takes some work. ${ }^{12}$ But if some explanation along the lines of Butler's idea does turn out to be correct, this would have several important implications for the prospects of the paradox of hedonism objection.

First, such an explanation would go some way toward answering the worry that the paradox of hedonism is a merely empirical issue. In fact, I have argued elsewhere that if we accept a Butler-style account, we can expect the paradox of hedonism not only for creatures with the quirks of our psychology, but for all rational (and well-informed) agents. ${ }^{13}$

Second, if this sort of explanation turns out to be correct, then this would mean that the paradox of hedonism is not only a problem for egoistic hedonists, that is, people who care only about their own pleasure. This is true for two reasons.

First, suppose that the only thing that you intrinsically desire is pleasure, but that you are not solely concerned with your own pleasure; you also intrinsically desire the pleasure of others. In that case, you may be able to take pleasure in seeing other people happy, since that would satisfy one of your intrinsic desires. But if Butler's idea is right, then it looks like the pleasure of others will be your only possible ultimate source of pleasure. After all, the idea is that pleasure can come only from the satisfaction of independent desires, but if we set aside your altruistic desires, you have no independent desires to work with. You will not be able to find any pleasure in your own life; that is, you will not be able to find pleasure from non-altruistic interests in things such as eating pizza, watching movies, or hiking, since by hypothesis, you have no such interests. So even if you are not an egoist, you will still be subject to a limited version of the paradox.

Second, if Butler's idea is right, then we can predict that there will also be a collective version of the paradox, which would apply to non-egoistic hedonists. ${ }^{14}$ That is, suppose that we are all hedonists in the sense that pleasure is the only thing that each of us intrinsically desires, but that it need not be her own pleasure; each of us also intrinsically desires the pleasure of others. Even so, in

11 For an introduction to the contemporary debate on the nature of pleasure, see Bramble (2016b). For a contemporary statement and defense of the desire theory, see Heathwood (2007).

$12 \operatorname{Dietz}(2019)$.

13 Ibid.

14 Dietz (2019): 508-509. 
that case, we can predict that no one in the group will be able to obtain pleasure, since then none of us would have independent desires to satisfy.

If Butler's idea is right, then, the paradox of hedonism is not merely an empirical issue of human psychology, but rather applies to rational agents more generally; and the paradox does pose significant issues for non-egoistic hedonists, as well as egoistic hedonists. We can capture these points in the following revised statement of the paradox:

The paradox of hedonism (revised version): If we are rational, and we intrinsically desire nothing other than pleasure, then we will be significantly prevented from obtaining pleasure.

This is purposely vague: the ambiguous "we," and the notion of "significant" limits, enables us to use this formulation as a brief description to capture both the individualistic and collective versions of the paradox arising for non-egoistic agents.

In short, it matters if Butler's idea is the right explanation of the paradox. If Butler's idea is right, then the problem is not that we're unlucky, or that we're stupid, or that we're selfish. Rather, the problem is that pleasure is not the right sort of object to which to devote our desires.

\subsection{What the Problem Is}

Now that we have considered the nature of the paradox of hedonism as a psychological phenomenon, I will lay out how we can use the paradox as an objection to hedonism about well-being.

Our first step in formulating the paradox of hedonism objection is to clarify its target. My proposed version of the objection will not target all hedonists about well-being, but rather those who are also committed to the welfarist view that the only things which are intrinsically desirable are those things which contribute to well-being. ${ }^{15}$ In other words, my objection will target the following view:

Axiological hedonism: What is intrinsically good for subjects, and (therefore) what is intrinsically desirable simpliciter, is (just) pleasure.

This is a significant caveat, because welfarism is not uncontroversial. One might well accept a hedonistic theory of well-being without accepting a hedonistic theory of value. However, it is highly attractive to think that well-being is the

15 For discussion of this issue, see Bramble (Forthcoming). 
only, or at least the main, component of what is valuable. This is a big part of why the nature of well-being is a central issue in moral philosophy. In addition, if it turned out that defending a hedonistic theory of well-being required us to give up on welfarism, that would be a highly significant result.

Now, suppose that axiological hedonists are willing to grant that pleasure is not the right sort of object to which to devote our desires. Even so, they might point out, we have not yet made it clear why that is supposed to be a problem for them. Axiological hedonists don't claim that we ought to devote ourselves to pleasure; they just claim that pleasure is what's intrinsically desirable.

Here is how I propose to use the paradox of hedonism make trouble for axiological hedonism. We should claim that if we believe in axiological hedonism, this will push us toward devoting our desires to pleasure, and thus into the predicament described by the paradox of hedonism. This is because there is an important general connection between our evaluative beliefs and our desires.

Moreover, we should claim that this connection, once again, is not just an empirical fact about human moral psychology, but rather a rational connection, a connection that would apply to rational agents of any kind. So believing in axiological hedonism would push any rational agents into the paradox of hedonism. This is a problem, we can claim, because it is plausible that an axiological theory ought to "work," in some sense, when accepted by rational agents.

In short: not only is pleasure the wrong sort of object to which to devote our desires, but it is also the wrong sort of object to treat as ultimately desirable.

What is the relevant rational connection between evaluative beliefs and desires? For our purposes, we can rely on the following negative connection: that once you come to believe that something is not desirable (even if it is not positively undesirable), this will prevent you from rationally desiring it. That is, we can claim:

Rational Desire: If you are rational, then if you believe that $\mathrm{X}$ is not (intrinsically) desirable, you will not (intrinsically) desire X.

I will argue that there are a number of good reasons for accepting this claim, and that the claim can be defended against some natural objections.

Finally, we can express the idea that an axiological theory ought to "work" when accepted by rational agents as

the acceptability requirement: Other things equal, we should reject an axiological theory if rational agents who accepted its claims about which objects were intrinsically desirable would be significantly prevented from obtaining those objects. 
Now we are in a position to lay out the objection explicitly.

P1. Rational Desire: If you are rational, then if you believe that $\mathrm{X}$ is not (intrinsically) desirable, you will not (intrinsically) desire X.

$\mathrm{P} 2$. If axiological hedonism is true, then pleasure is the only thing that is intrinsically desirable. Thus, if you believe in axiological hedonism, you will believe that nothing other than pleasure is intrinsically desirable.

C1. Therefore, rational agents who believe in axiological hedonism will intrinsically desire nothing other than pleasure. (from $\mathrm{P}_{1}$ and $\mathrm{P}_{2}$ )

$\mathrm{P}_{3}$. The paradox of hedonism: If we are rational, and we intrinsically desire nothing other than pleasure, then we will be significantly prevented from obtaining pleasure.

C2. Therefore, rational agents who believe in axiological hedonism will be significantly prevented from obtaining pleasure. (from $\mathrm{C}_{1}$ and $\mathrm{P}_{3}$ )

$\mathrm{P}_{4}$. The acceptability requirement: Other things equal, we should reject an axiological theory if rational agents who believe in its claims about which objects are intrinsically desirable will be significantly prevented from obtaining those objects.

$\mathrm{C}_{3}$. Therefore, other things equal, we should reject axiological hedonism. (from $\mathrm{P}_{2}, \mathrm{C}_{2}$, and $\left.\mathrm{P}_{4}\right)^{16}$

Below, I will defend two of this objection's key premises, the acceptability requirement and Rational Desire. In doing so, I aim to show that the objection does indeed constitute a formidable challenge for hedonism. However, I want to point out that even if these defenses are not successful, we can still draw a significant lesson from this objection. Since the argument is clearly valid, it shows that we face an inconsistent set: Rational Desire, the acceptability requirement, the paradox of hedonism, and axiological hedonism, as I

16 It is important to note that this challenge is related to a parallel set of challenges for consequentialist theories. It has been observed that there is a parallel "paradox of consequentialism," that is, that thinking in consequentialist terms can prevent agents from producing the best consequences. See Williams (1973), Stocker (1976), Railton (1984), Wiland (2007), and Eggleston (2013b). One response to this worry has been to argue that even if it would be a bad idea for agents to believe in or try to follow a consequentialist theory, this does not mean that the theory is incorrect. See Hare (1981: 38), Railton (1984: 152-156), Parfit (1984: 23-29, 40-45), and Scheffler (1994: 44-52). The parallel response in this context would be to deny our acceptability requirement. A second response to the worry has been to try to explain how accepting a consequentialist theory need not in fact lead to problematic consequences (for example, Railton's (1984) "sophisticated consequentialism"). The parallel response in this context would be to deny Rational Desire, and thus to argue that we could accept hedonism without falling into the paradox of hedonism. 
have formulated them, cannot all be correct. ${ }^{17}$ So, for example, the objection shows that if we want to accept axiological hedonism, but we also acknowledge the paradox of hedonism, then we must reject either Rational Desire or the acceptability requirement. This is significant, because a number of philosophers are attracted to versions of each of these claims, and it was not obvious that they were in tension. ${ }^{18}$

\section{3}

\section{The Scope of the Problem}

In this section, I argue that if the paradox of hedonism is in fact a problem for hedonism about well-being, then it also indicates a more general problem, which poses a challenge for other leading theories of well-being.

As we have seen, Butler suggests that the paradox of hedonism arises in virtue of the fact that the nature of pleasure involves a close connection to desire satisfaction. Pleasure has to do with satisfying your desires, but if all you desire is pleasure itself, you will be stuck. According to our objection, this is a problem for welfare hedonists, because it seems that any rational agents who believe in hedonism about welfare would end up in this very predicament.

But the problem is not limited to hedonism about well-being. First, note that we can see Butler's account of the paradox of hedonism as relying on the following more general insight:

The paradox of desire satisfaction: Insofar as the only states of affairs that you desire themselves involve the satisfaction of your desires, these states will not be realized.

Again, if Butler is right that pleasure is closely connected to desire satisfaction, then this means that we had better avoid investing ourselves in pleasure. But we had also better avoid investing ourselves in any other object that is too closely connected to desire satisfaction.

17 I owe this point to an editor.

18 As noted below, Rational Desire is a weaker variant of the "guise of the good" doctrine to which many philosophers have been sympathetic; for an overview of the contemporary literature on this issue, see Orsi (2015). Discussions sympathetic to views similar to the acceptability requirement can be found in the literature on indirect consequentialism (see previous note); they include Williams (1973) and Wiland (2007). On the paradox of hedonism, see Dietz (2019). Contemporary defenses of hedonism include Feldman (2004) and Bramble (2016a). 
Now consider two of the other leading theories of well-being: desire satisfactionism and the hybrid theory. Roughly, desire satisfactionism claims that well-being consists in desire satisfaction. As a first pass, we can formulate this view more precisely as follows:

Desire satisfactionism: What is intrinsically good for someone is (just) the satisfaction of their desires; what is intrinsically bad for someone is (just) the frustration of their desires. ${ }^{19}$

Roughly, the hybrid theory claims that well-being consists in obtaining certain special "objective" states, such as knowledge, achievement, or love, while also meeting certain "subjective" conditions, such as desiring or valuing these states. As a first pass, we can formulate this view more precisely as follows:

Hybrid theory: What is intrinsically good for us is to obtain [knowledge, achievement, love, etc.] while intrinsically desiring to obtain them.

But we can now see that these views are also in trouble. First, if welfarism is correct, then desire satisfactionism will imply the axiological view that desire satisfaction is the only thing that is intrinsically desirable. And if Rational Desire is correct, then rational agents who accept this axiological view will end up intrinsically desiring nothing other than desire satisfaction. But then they will face the paradox of desire satisfaction: if all we desire is desire satisfaction itself, we'll be stuck.

Surprisingly, the hybrid theory faces the same problem. If welfarism is true, then the hybrid theory will imply the axiological view that what is intrinsically desirable is obtaining the relevant objective states while intrinsically desiring to obtain them. And if Rational Desire is correct, then rational agents who accept this axiological view will end up intrinsically desiring nothing other than complex states such as these: having friends while intrinsically desiring to have friends. But because these agents would only be desiring states which involve desire satisfaction itself, they too would face the paradox of desire satisfaction. After all, if the only thing you intrinsically desire is a complex state like 'having friends while intrinsically desiring to have friends,' then you won't

19 As we will see below, another way of formulating desire satisfactionism is to assign intrinsic welfare value to the objects of one's desires, rather than to the fact that one's desires have been satisfied. I will argue that the paradox of desire satisfaction gives us a reason to favor this alternative formulation, as well as analogous formulations of hedonism and the hybrid theory. 
have an intrinsic desire for the simple state of 'having friends,' which means that the complex state will not be realized.

It might be objected that, when we intrinsically desire a complex state of affairs like 'having friends while intrinsically desiring to have friends,' we must thereby intrinsically desire to have friends, since this is part of the complex state. But this thought is confused. Even though having friends is part of what we desire for its own sake, that doesn't mean we desire the part for its own sake; on the contrary, we desire it only because it is part of a larger whole. And if this thought were true, then in intrinsically desiring to have friends, we would have to be failing to conform with Rational Desire, since by hypothesis, we believe that having friends is not intrinsically desirable.

Interestingly, desire satisfactionism and the hybrid theory are actually more susceptible to this problem than hedonism about well-being. This is because using the paradox of desire satisfaction to explain the paradox of hedonism requires Butler's assumption that the nature of pleasure involves a close connection to desire satisfaction. Again, the idea that pleasure can be understood in terms of desire remains prominent in the contemporary literature, but it is debatable: a plausible alternative theory is that pleasure is to be understood in purely phenomenological terms. ${ }^{20}$ By contrast, it is not debatable whether desire satisfaction is to be understood in terms of desire satisfaction, or whether 'having friends while desiring to have friends' essentially involves desire satisfaction.

In short, the paradox of hedonism is a symptom of a more general problem, the paradox of desire satisfaction. This problem is a challenge for hedonism about well-being, but only if, and because, pleasure turns out to be explainable in terms of desire. And the problem is a challenge not only for hedonism, but rather for all theories of well-being that essentially involve desire satisfaction.

So far, I have laid out a version of the paradox of hedonism objection, and argued that it is a symptom of a deeper problem facing all desire-based theories of welfare. I will now defend two of the objection's key premises. In this section, I will defend the acceptability requirement; in the next section, I will defend Rational Desire.

Why should we accept the acceptability requirement? Why should we accept that, other things equal, we should reject an axiological theory if

20 For a defense of this theory, see Bramble (2013). 
rational agents who accepted its claims about which objects were intrinsically desirable would be significantly prevented from obtaining those objects?

The acceptability requirement is a natural consequence of the common idea that a central role that ethical claims are supposed to play is to provide us with guidance. We are interested in finding out what we ought to do in order to influence our decisions. And we are interested in finding out what is truly desirable in order to influence what we care about. We hope that philosophical reflection will help us to live well. If accepting a particular philosophical view would prevent us from living well, we might think then that can be a significant mark against that view.

For similar reasons, while the acceptability requirement focuses on axiological theories, philosophers have long taken seriously - though not always endorsed - analogous constraints on theories of right action. In particular, the idea that accepting a consequentialist ethical theory might prevent one from achieving the best consequences has been taken to be a significant challenge for consequentialism. ${ }^{21}$

Moreover, note that the acceptability requirement qualifies the idea that ethical claims should provide us with helpful guidance in two ways. First, it incorporates an "other things equal" clause. This means that, if on other grounds we found one axiological theory much more compelling than the alternatives, the requirement allows that that theory could be correct. The requirement allows, in other words, that the truth could turn out to be bad for us. If there is not otherwise a clear winner, however, the requirement suggests that the "unacceptability" of some views could make a difference.

Second, note that the requirement focuses on what it would be like for rational agents to accept an axiological theory. This reflects the idea that the correctness of a philosophical view should not depend on contingent empirical issues. If it would be bad for us to accept an axiological theory only because of bad luck - for example, because we would tend to apply the theory incorrectly, or because an evil demon will punish us for believing the theory - then it is reasonable to be skeptical that that casts doubt on the correctness of the theory. After all, as several philosophers have pointed out, we could imagine situations in which similar problems would arise for any theory. ${ }^{22}$ But we might think that an axiological theory should at least "work" for rational agents, at least when we do not imagine them in particularly unfavorable circumstances. If it does not, then again, we might take this to indicate that the theory has identified the wrong sort of object as intrinsically valuable.

21 See note 16.

22

Parfit (1984: Sect. 18) and Eggleston (2013b). 
I will now defend the other key premise of my proposed version of the paradox of hedonism objection: Rational Desire, the claim that it is irrational to (intrinsically) desire what we believe is not (intrinsically) desirable. ${ }^{23}$

I will start by laying out six reasons for accepting Rational Desire; then I will defend this claim against some important objections.

\subsection{Six Reasons to Accept Rational Desire}

The first reason to accept Rational Desire is simply that it has considerable intuitive plausibility. It is plausible that if I recognize that something is not in any way desirable (again, even if it is not positively undesirable), but I still want it nevertheless, then my desire-forming mechanisms are not functioning properly. As T. M. Scanlon puts it, desires would "be extinguished" in an ideally rational person who judged them not to be supported by reasons. ${ }^{24}$

The second reason to accept Rational Desire is that this claim can be supported by parallels with at least some other attitudes. For example, it is plausible that if I am convinced that someone's accomplishments are not admirable, then the rational way for me to respond would be to stop admiring them; that if I am convinced that someone's position is not enviable, then the rational way for me to respond would be to stop envying it; and that if I am convinced that someone is not deserving of pity, then the rational way for me to respond would be to stop pitying her. ${ }^{25}$

The third reason is that it seems that we can and do exploit the connection described by Rational Desire for therapeutic purposes. That is, if we find ourselves with some particular desire that we would like to get rid of, one way to do that is to try to convince ourselves that there is nothing desirable about the relevant object. And it is plausible that this would be a rational response, not merely a weird quirk of human psychology. For example, suppose that I no longer have time to go bird-watching, but still find myself feeling the itch, which I find distracting and frustrating. A reasonable solution, it seems, would be to

23 Strictly speaking, the argument relies only on the claim about the connection between what we intrinsically desire and what we believe to be intrinsically desirable. However, I find it easier to think about this claim as part of a broader view about the connection between our desires and our evaluative beliefs.

24 Scanlon (1998: 20). See also Stocker (1976: 453-455) and Parfit (1984: 123).

25 An editor suggests that it is not as clear that this pattern holds for some attitudes: in particular, for attitudes concerning "matters of taste." For example, perhaps it is not irrational to be amused by a joke that one believes is not funny. However, I myself still find this combination of responses dissonant. I discuss matters of taste further below. 
try to convince myself that bird-watching is pointless anyway. Similarly, the Stoics, Epicureans, and Skeptics explicitly used philosophical arguments about what objects are truly desirable as a means to help us overcome unhealthy desires and emotions. ${ }^{26}$ While we may or may not find these arguments to be effective, it seems that this strategy is not entirely on the wrong track.

The last three reasons for accepting Rational Desire come from considering specific examples where we desire something that we believe is not desirable.

First, there are cases of disillusionment. In particular, many of us, I think, have had the experience of coming to see something that we had been invested in, as pointless or worthless, and of losing interest in this thing as a result. ${ }^{27}$ For example, suppose you find yourself obsessed with beating a video game, when it suddenly occurs to you that whether you beat the game or not really doesn't matter. Winning would be a meaningless achievement, in no way worth desiring. In this case, it is plausible that you would be displaying irrationality if your passion for winning the game persisted unchanged.

Second, there are cases where someone believes that something is uniquely desirable in some way (directly parallel to the cases which we are interested in, where someone believes that pleasure is the only thing that is intrinsically desirable). In these cases, it is plausibly irrational for a person to desire the alternatives that she considers not to be desirable. For example, suppose that you know a medical student who claims that the only desirable specialty is surgery. It would be surprising, and confusing, if you found out that she had her heart set on dermatology. Similarly, it would be odd for a friend to claim that the only city it was desirable to live in is New York, but that he couldn't wait to move to Omaha.

Finally, there is the case of nihilism: the belief that nothing matters. Rational Desire can provide us with a plausible explanation of why coming to hold this belief would plausibly have major, and seemingly appropriate, psychological repercussions. In particular, when we come to doubt that anything matters, it seems to strike us as irrational to continue caring about much of what we now care about. ${ }^{28}$ For example, consider Tolstoy's description of his existential crisis:

My life came to a standstill. I could breathe, eat, drink and sleep, and I could not help breathing, eating, drinking and sleeping; but there was

26 For discussion of these arguments, see Nussbaum (2009).

27 Compare Kahane (2017: 339).

28 See Bramble (2013: 215) and Kahane (2017: 339-341). 
no life in me because I had no desires whose gratification I would have deemed reasonable to fulfil. ${ }^{29}$

Tolstoy's account suggests that when he experienced his existential crisis, his desires actually did substantially diminish as a result of coming to believe that their objects did not have value. In his famous discussion of "the absurd," Nagel suggests another possibility. According to Nagel, when we suspect that nothing objectively matters, we do not lose our ordinary concerns, but we do start to regard them as absurd. ${ }^{30}$ If so, this also supports Rational Desire, since plausibly, it is not rational to have concerns that you yourself regard as absurd.

\subsection{The Guise of the Good}

Next, note that Rational Desire is not quite as strong as some more familiar views about the relation between our desires and our normative beliefs. In particular, a traditional idea is that we desire things under a "guise of the good," that is, your desiring something involves your believing that it is good, or its appearing good to you, or there appearing to be normative reasons in favor of having it. ${ }^{31}$ Another way of spelling out this idea would be to suggest that while it is not impossible to desire something without believing that it is good, it is irrational to do so; in other words, we rationally ought to desire only what we believe to be good.

These views, we might think, are implausibly strong. After all, it seems obvious that creatures such as cats or babies desire things, but it might seem doubtful that these creatures have normative concepts. It might also seem plausible that, like these other creatures, more sophisticated human beings also naturally come to desire things without forming beliefs about their goodness or desirability. And moreover, it might not seem that there is anything wrong with these desires.

Luckily, these worries do not apply to Rational Desire. Rational Desire does not claim that in order to desire something, or in order to desire something rationally, we must believe that it is desirable. The view only claims that, once we come to believe that something is not desirable, then we cannot rationally continue to desire it.

29 Tolstoy (1882: 30).

$30 \quad$ Nagel (1971).

31 For an introduction to the "guise of the good" tradition, see Orsi (2015). 


\subsection{The Matters of Taste Objection}

I have argued that we have a number of reasons to accept the claim that it is irrational to (intrinsically) desire something that you believe is not (intrinsically) desirable. However, against this claim, it might be objected that there are surely certain things, such as which ice cream flavors we like and dislike, which are simply a matter of taste. In these cases, it seems, it is not irrational to intrinsically desire the relevant objects, even while believing that they are not intrinsically desirable.

For example, it is plausible that most of us would deny that there is anything intrinsically desirable about the experience of tasting chocolate ice cream. Rather, most of us would acknowledge that this is just something that some people happen to like. As Sobel writes, we might say that "everyone has more reason to taste chocolate rather than strawberry ice cream as the former is an intrinsically more valuable flavor," but "[t] his is something most of us say only when joking." ${ }^{32}$ Yet surely there is nothing irrational about desiring to taste chocolate ice cream.

My first response to this objection is that it is not clear that people who intrinsically desire the taste of chocolate ice cream really believe that this taste is not "intrinsically" desirable in the relevant sense. ${ }^{33}$

Recall that for the purposes of this discussion, we have been using the notion of "intrinsic" value to mean what is valuable for its own sake, rather than because it will lead to other valuable things. This contrasts with the stricter notion of intrinsic value as value derived solely from the object's intrinsic properties. In our sense, for something to have "intrinsic" value, its value must not be explained by its having certain sorts of relation to other valuable things; but this is compatible with the idea that its value might have some other kind of explanation. ${ }^{34}$ As we will see, this idea will play an important role in the next section.

When we claim that the taste of chocolate ice cream is not "intrinsically" desirable, then, it may be that what we are really trying to say is that the value

32 Sobel (2005: 445). See also Parfit (1984: 123).

33 Another natural reply would be that we do not really desire the taste of chocolate ice cream intrinsically, but merely instrumentally: what we desire intrinsically is the pleasure that we expect that tasting the ice cream will bring us. If so, then since pleasure is plausibly something that we do think is intrinsically desirable, such cases would no longer represent counterexamples to Rational Desire. However, I am not inclined to make this reply, because I find it plausible that we would not derive pleasure from things like chocolate ice cream unless we intrinsically desired these things in the first place, a point famously made by Butler (1726: 365). For recent discussion of Butler's argument, see Tilley (2018).

34 Again, for introductions to the issues surrounding the concept of intrinsic value, see Rønnow-Rasmussen (2015) and Zimmerman and Bradley (2019). 
of this experience does not derive solely from the intrinsic properties of the experience, but rather has a further explanation. In particular, what we really think, might be that the value of the experience derives from additional features of one's psychology, such as the fact that one desires or likes the experience. ${ }^{35}$ Moreover, because these further psychological features might not be shared by everyone, this interpretation would make sense of why we might not seriously claim that everyone has reason to taste chocolate ice cream.

My second response to the objection is to point out that Rational Desire is compatible with another plausible account of the idea that some things are "matters of taste": that two people can have different tastes without either of them being irrational, and without disagreeing in their evaluative judgments about the objects.

For example, suppose that I love chocolate ice cream, but strawberry isn't really my thing, whereas you're the reverse. Suppose that we are both willing to grant that the tastes of both chocolate and strawberry ice cream are intrinsically desirable. And suppose that we even believe that both tastes are desirable in virtue of the intrinsic features of the experience, and so that either experience would be desirable for either of us to have.

In that case, does Rational Desire imply that I am being irrational for failing to intrinsically desire to taste strawberry ice cream, and that you are being irrational for failing to intrinsically desire to taste chocolate ice cream? No. Again, Rational Desire does not claim that a rational agent has to desire whatever she believes is desirable. It claims only that a rational agent will not desire things that she believes are not desirable. ${ }^{36}$

I have now laid out my version of the paradox of hedonism objection, and have made the case in defense of two of its key premises. I have also argued that the paradox of hedonism not only presents a challenge to hedonism about

35 Note that Sobel's remark in fact comes in the course of defending a desire-based theory of normative reasons, which is closely related to the view that I am describing here.

36 Would there be something oddly asymmetrical about claiming both that it is rationally forbidden to desire what one believes is not desirable, but also that it is not rationally required to desire what one believes is desirable? (Thanks to an editor for raising this worry.) I don't find this too weird. I like to think of the analogy of visiting an art museum. It seems to me that there would be something inappropriate about admiring an artwork that one recognized as having absolutely no merit. But it is also plausibly not obligatory to admire each and every one of the artworks that one believes does have merit. 
well-being, but that it indicates a deeper problem, the paradox of desire satisfaction, which presents a challenge to all desire-based theories of well-being.

In this section, however, I will offer a solution to this challenge: what we can call the backgrounding move. This move has previously been discussed in the literature on desire satisfactionism, largely in response to independent concerns. ${ }^{37}$ I will suggest here that it can provide us with a general solution to the paradox of desire satisfaction.

Up to this point, we have been working with the following formulations of hedonism, desire satisfactionism, and the hybrid theory:

Hedonism: What is intrinsically good for someone is (just) the pleasure they experience; what is intrinsically bad for someone is (just) the displeasure they experience.

Desire satisfactionism: What is intrinsically good for someone is (just) the satisfaction of their desires; what is intrinsically bad for someone is (just) the frustration of their desires.

Hybrid theory: What is intrinsically good for someone is to obtain [knowledge, achievement, love, etc.] while intrinsically desiring to obtain them.

As we have seen, if welfarism is correct, then these theories imply the axiological theories that pleasure, desire satisfaction, and the complex state of desiring an objective good are what are intrinsically desirable. But if Rational Desire is correct, then rational agents who believed in these axiological theories would end up desiring nothing other than pleasure, desire satisfaction, and the relevant complex states, and thus find themselves experiencing the paradox of desire satisfaction.

We can avoid this problem, I suggest, by revising how we formulate these theories. Again, the model for how to do this has been provided in the literature on desire satisfactionism.

There are two standard ways to formulate desire satisfactionism: the satisfaction formulation and the object formulation. ${ }^{38}$ The satisfaction formulation is the one presented above. This claims that what is intrinsically good for someone - and therefore, what is intrinsically good for someone - is the fact that one of their desires has been satisfied. In contrast, the object formulation

37 Rabinowicz and Österberg (1996) and Weelden (2019). Two importantly related discussions, on similar issues for desire-based theories of motivation and of normative reasons, respectively, are Pettit and Smith (1990) and Schroeder (2007: chap. 2).

38 Rabinowicz and Österberg (1996) and Weelden (2019). 
ascribes intrinsic welfare value to the objects of our desires rather than on the fact of desire satisfaction itself:

Desire satisfactionism (object formulation): $\mathrm{X}$ is intrinsically good for $\mathrm{S}$ just when and because $\mathrm{S}$ desires $\mathrm{X}$.

The object formulation departs from the satisfaction formulation in its enumerative claim: its claim about which natural state intrinsically contributes to well-being. ${ }^{39}$ For example, if I desire to go hiking, the object formulation claims that hiking will be intrinsically good for me, not the fact that I am satisfying a desire.

But the object formulation is still recognizably a version of desire satisfactionism. This is because it retains desire satisfactionism's core explanatory claim: that my welfare is to be explained by the fact that my desires have been satisfied. But this fact does not itself contribute to my well-being; rather, it operates in the background, explaining why the object of my desire makes me better off.

We can now see how agents who accept the object formulation of desire satisfactionism will be able to avoid the paradox of desire satisfaction. Again, if I desire to go hiking, then the object formulation implies that hiking is intrinsically good for me. This means that I will rationally be able to desire to go hiking for its own sake. And since hiking does not essentially involve desire satisfaction, I will not be caught in a vicious circle; I can simply go hiking, and my desire will be satisfied.

Now, the satisfaction formulation and the object formulation each have their proponents, and other arguments have been offered in favor of the satisfaction formulation. ${ }^{40}$ My point here is just that one significant advantage of the object formulation is that it can avoid the paradox of desire satisfaction.

The object formulation of desire satisfactionism serves as our model for the more general technique that we are calling "the backgrounding move." This move starts with the distinction between the explanatory and enumerative claims made by normative theories. The abstract form of these claims is as follows:

Explanatory claim: A state's having a certain normative property is explained by its having certain natural properties.

39 For an introduction to the "enumerative/explanatory" distinction, see Lin (2017).

40 For arguments in favor of the satisfaction formulation, see Rabinowicz and Österberg (1996), Bradley (2009: 25-30), Lukas (2010: 3), and Sarch (2011: 179-181). For arguments in favor of the object formulation, see Rabinowicz and Österberg (1996) and Weelden (2019). 
Enumerative claim: A certain natural state is what intrinsically has a certain normative property.

Hedonism, desire satisfactionism, and the hybrid theory make the explanatory claim that a state of affairs has the normative property of being good for someone because of its relations to pleasure, desire satisfaction, or a certain complex state. And our original formulations of these theories make the enumerative claim that pleasure, desire satisfaction, or the relevant complex state are what intrinsically contribute to well-being.

To make the backgrounding move, then, is to claim that the natural state which explains the normative property need not do this by itself possessing the normative property. Instead, the natural state operates in the background, explaining why other natural states possess the normative property.

Again, on the object formulation, desire satisfactionists claim that desire satisfaction need not itself be intrinsically good for us, but rather that it explains why other natural states are intrinsically good for us. But hedonists and hybrid theorists, I suggest, could make the same move: they could deny that pleasure or the relevant hybrid state are intrinsically good for us, but rather claim that these states make other natural states intrinsically good for us. ${ }^{41}$ (In the terms of our formal statement of the paradox of hedonism objection, this means that hedonists could deny $\mathrm{P}_{2}$, the definitional premise stating that hedonists take pleasure to be the only thing that is intrinsically desirable.)

What other natural states could hedonists and hybrid theorists focus on? Hedonists could reformulate their view in a directly analogous way. After all, pleasure, like desire, has objects: there are things we take pleasure in, or are pleased about. ${ }^{42}$ Thus, hedonists could claim:

Hedonism (object formulation): $\mathrm{X}$ is intrinsically good for $\mathrm{S}$ just when and because $\mathrm{S}$ takes pleasure in $\mathrm{X}$.

41 Daniel Pallies brought my attention to this way of formulating hedonism. Pallies (ms.) explores how a related strategy might help hedonists to avoid the experience machine and philosophy of swine objections.

42 An editor suggests that pleasure might not always have objects, as distinguished from mere causes: there might be cases of "pure affect," pleasure that is not about anything at all. This is particularly plausible on purely phenomenological theories of pleasure. However, as discussed earlier, I have been relying here on the assumption that some desire-based theory of pleasure is correct. And since desires, presumably, do always have objects, I take it that desire-based theories of pleasure will be committed to denying the possibility of pure affect. 
Hybrid theorists could reformulate their view in a similar, if not directly analogous, way: they could focus on the objects that are part of the complex state that they take to be fundamental for welfare. In other words, they could claim:

Hybrid theory (object formulation): $\mathrm{X}$ is intrinsically good for $\mathrm{S}$ just when and because $\mathrm{X}$ is a state of [knowledge, achievement, love, etc.] and $\mathrm{S}$ intrinsically desires $\mathrm{X}$.

As with desire satisfactionism, this move would allow hedonists and hybrid theorists to escape the paradox of desire satisfaction. If I take pleasure in hiking, then hedonists can claim that hiking is intrinsically good for me, so believing that hedonism will be rationally compatible with intrinsically desiring hiking. Similarly, if hiking is an instance of some objective good such as achievement, then believing the hybrid theory will also be rationally compatible with intrinsically desiring hiking. So on either view, I will be able to intrinsically desire objects that do not essentially involve desire satisfaction itself. ${ }^{43}$

Would there be anything distinctive about the psychology of a rational agent who accepted one of these theories? I suggest that the psychology of such an agent would reflect something like Railton's "counterfactual condition." ${ }^{\text {"4 }}$ That is, while agents would intrinsically desire objects other than desire satisfaction, pleasure, or the relevant complex states, they would stop desiring these things if they came to believe that these objects did not have the appropriate relation to desire satisfaction, pleasure, or the relevant complex states. In particular, a desire satisfactionist would no longer intrinsically desire, say, hiking, if she came to believe that it was not the object of the right sort of intrinsic desire; a hedonist would no longer intrinsically desire hiking if she came to believe that it was not an object of pleasure; and a hybrid theorist would no

43 Daniel Pallies brought to my attention another interesting way in which we might reformulate these theories: we might claim that intrinsic welfare value is possessed both by the normatively fundamental states (desire satisfaction, pleasure, or a hybrid state) and by the associated "objects." For example, we could consider a version of desire satisfactionism according to which two things have intrinsic welfare value: the objects of our desires and the satisfaction of our desires. (Compare Lin's (2016b) "subjective list theory," which assigns welfare value to both actual desire satisfaction and subjective desire satisfaction - roughly, believing that you're getting what you want.) We could accept this theory without running into the paradox of desire satisfaction (since it allows that desire satisfaction is not the only thing with intrinsic welfare value), and it would also allow us to retain desire satisfaction as part of its enumerative claims. Similarly, a hedonist might assign intrinsic welfare value both to pleasure and to its objects, and a hybrid theorist might assign intrinsic welfare value both to hybrid states and to the constituent objects.

Railton (1984: 144-145). 
longer intrinsically desire hiking if she came to believe that it was not part of the right sort of complex state.

Why would our agents have this sort of psychology? Because these agents would believe that these objects would not be intrinsically desirable if they were not related to these states, and so Rational Desire would prevent the agent from desiring these objects. The backgrounding move thus allows us to preserve Railton's insight about what a sophisticated ethical psychology might look like without running afoul of Rational Desire.

The distinction between the satisfaction and object interpretations of desire satisfactionism grew out of a distinction made in desire-based theories of motivation; a similar distinction has also been made with regard to desire-based theories of normative reasons. ${ }^{45}$ But again, we can see the basic underlying thought as a more abstract point about how we can structure normative theories. The natural state that operates in the background need not be desire: it could be pleasure or a hybrid state. It could even be some purely "objective" state; for example, an objective list theorist might claim that the fact that something is an achievement can make that event intrinsically good for me. But for our purposes, the important point is that desire-based theories of welfare can make use of the backgrounding move to avoid the paradox of desire satisfaction.

In this paper, I have argued that we can use the paradox of hedonism to create a challenge for hedonistic theories of well-being. We cannot merely dismiss the paradox of hedonism as an empirical inconvenience, or as a problem only for egoists. Instead, we can argue that any rational agents who accept standard versions of hedonism about well-being, together with a welfarist theory of value, will find themselves experiencing the paradox of hedonism, prevented from obtaining what hedonists claim to be desirable. And it is plausible that this suggests that pleasure is not the right kind of object to identify as what is ultimately desirable. In addition, I noted that even if this argument is not successful, there is still an important lesson to draw: that the main views at issue in the argument, each of which have been attractive to a number of philosophers, in fact form an inconsistent set.

45 See Pettit and Smith (1990) and Schroeder (2007: chap. 2). For a helpful overview, see Weelden (2019: 139-144). 
I have also argued that the paradox of hedonism, if it is a problem at all, is in fact a symptom of a deeper problem, the paradox of desire satisfaction, which challenges all theories which claim that satisfying our desires is an essential part of well-being. Lastly, however, I argued that these theories can escape the problem by making the backgrounding move. That is, these theories could claim that pleasure, desire satisfaction, or a hybrid of objective and subjective conditions are not themselves intrinsically good for us, but rather that they operate in the background, making other states intrinsically good for us.

The paradox of hedonism objection, and the broader paradox of desire satisfaction objection, then, raise significant issues for theories of well-being. As with the standard objections to hedonism, desire satisfactionism, and the hybrid theory, they force us to confront potentially uncomfortable aspects of the theories: in this case, facts about what it would be like to believe these theories. And they challenge us to develop stronger versions of these theories.

\section{Acknowledgements}

For helpful feedback and discussion, I would like to thank Nathan Robert Howard, Daniel Pallies, Edgar Phillips, Abelard Podgorski, Jonathan Quong, Mark Schroeder, and an audience at the British Society for Ethical Theory.

\section{Biographical Note}

Alexander Dietz is Lecturer in Philosophy at Cardiff University. His research interests include collective reasons for action, well-being, value, moral psychology, and effective altruism.

\section{References}

Bradley, Ben. 2009. Well-Being and Death. Oxford University Press.

Bramble, Ben. 2013. "The Distinctive Feeling Theory of Pleasure." Philosophical Studies $162(2): 201-217$.

Bramble, Ben. 2016a. "A New Defense of Hedonism About Well-Being." Ergo: An Open Access Journal of Philosophy 3.

Bramble, Ben. 2016b. "The Role of Pleasure in Well-Being." In The Routledge Handbook of the Philosophy of Well-Being, edited by Guy Fletcher. 
Bramble, Ben. Forthcoming. "Welfarism." In The International Encyclopedia of Ethics, 2nd print edition, edited by Hugh LaFollette. Accessed at http://www.benbramble. com/research.html.

Broad, C. D. 193o. Five Types of Ethical Theory. Routledge.

Butler, Joseph. 1726 (1991). Fifteen Sermons Preached at the Rolls Chapel, in British Moralists, 1650-180o, Vol. 1, ed. D. D. Raphael, Hackett: 325-377.

Cohen, G. A. 2003. "Facts and Principles." Philosophy and Public Affairs 31 (3): 211-245.

Dietz, Alexander. 2019. "Explaining the Paradox of Hedonism." Australasian Journal of Philosophy 97 (3): 497-510. https://doi.org/10.108o/ooo48402.2018.1483409.

Eggleston, Ben. 2013a. "Paradox of Happiness." In The International Encyclopedia of Ethics, edited by Hugh LaFollette, 3794-3799. Wiley-Blackwell.

Eggleston, Ben. 2013b. "Rejecting the Publicity Condition: The Inevitability of Esoteric Morality." Philosophical Quarterly 63 (250): 29-57.

Feldman, Fred. 2004. Pleasure and the Good Life: Concerning the Nature, Varieties, and Plausibility of Hedonism. Clarendon Press.

Gregory, Alex. 2016. "Hedonism." In The Routledge Handbook of Philosophy of Wellbeing, edited by Guy Fletcher.

Hare, R. M. 1981. Moral Thinking: Its Levels, Method, and Point. Oxford: Oxford University Press.

Heathwood, Chris. 2007. "The Reduction of Sensory Pleasure to Desire." Philosophical Studies 133 (1): 23-44.

Kahane, Guy. 2017. "If Nothing Matters." Noûs, 51: 327-353.

Lin, Eden. 2016a. "How to Use the Experience Machine." Utilitas 28 (3): 314-32.

Lin, Eden. 2016b. "The Subjective List Theory of Well-Being." Australasian Journal of Philosophy 94 (1): 99-114.

Lin, Eden. 2017. "Enumeration and Explanation in Theories of Welfare." Analysis 77 (1): 65-73.

Lukas, M. 2010. "Desire Satisfactionism and the Problem of Irrelevant Desires." Journal of Ethics and Social Philosophy, 1-24.

Mill, John Stuart. 1873. Autobiography. In, John M. Robson, and Jack Stillinger, eds. Collected Works of John Stuart Mill, 2009. Vol. 1. Routledge.

Nagel, Thomas. 1971. "The Absurd." The Journal of Philosophy, 68: 716-727.

Nussbaum, Martha. 2009. The Therapy of Desire. Princeton: Princeton University Press.

Orsi, Francesco. 2015. "The Guise of the Good." Philosophy Compass 10 (10): 714-724.

Pallies, Daniel. "Hedonistic Explanations of Well-Being” (manuscript).

Parfit, Derek. 1984. Reasons and Persons. Oxford University Press.

Pettit, Philip, and Michael Smith. 199o. "Backgrounding Desire." Philosophical Review 99 (4): 565-592.

Rabinowicz, Wlodek, and Jan Österberg. 1996. "Value Based on Preferences." Economics and Philosophy 12 (1): 1-27. 
Railton, Peter. 1984. "Alienation, Consequentialism, and the Demands of Morality." Philosophy and Public Affairs 13 (2): 134-171.

Rønnow-Rasmussen, Toni. 2015. "Intrinsic and Extrinsic Value." In The Oxford Handbook of Value Theory, edited by Iwao Hirose and Jonas Olson. Oxford University Press.

Sarch, Alexander. 2011. "Internalism About a Person's Good: Don't Believe It." Philosophical Studies 154 (2): 161-184.

Scanlon, T. M. 1998. What We Owe to Each Other. Belknap Press.

Scheffler, Samuel. 1994. The Rejection of Consequentialism: A Philosophical Investigation of the Considerations Underlying Rival Moral Conceptions. Oxford University Press.

Schroeder, Mark. 2007. Slaves of the Passions. Oxford University Press.

Sobel, David. 2005. "Pain for Objectivists: The Case of Matters of Mere Taste." Ethical Theory and Moral Practice, 8: 437-457.

Stocker, Michael. 1976. “The Schizophrenia of Modern Ethical Theories.” The Journal of Philosophy, 73: 453-466.

Tilley, John J. 2018. “Butler's Stone." Pacific Philosophical Quarterly 99 (4): 891-9o9.

Tolstoy, Leo. 1882 (1987). A Confession and Other Religious Writings. Penguin Classics.

Weelden, Joseph van. 2019. "On Two Interpretations of the Desire-Satisfaction Theory of Prudential Value." Utilitas 31 (2): 137-156.

Wiland, Eric. 2007. "How Indirect Can Indirect Utilitarianism Be?" Philosophy and Phenomenological Research 74 (2): 275-301.

Williams, Bernard. 1973. “A critique of utilitarianism.” In, J. J. C. Smart, and Bernard Williams, Utilitarianism For and Against. Cambridge University Press.

Zimmerman, Michael J., and Ben Bradley. 2019. "Intrinsic vs. Extrinsic Value." Stanford Encyclopedia of Philosophy. https://plato.stanford.edu/archives/spr2o19/entries/ value-intrinsic-extrinsic/. 